\title{
Bilateral supernumerary primary teeth in the maxillary anterior region
}

\section{Seema Dinesh Bargale, ${ }^{1}$ Shital Kiran, ${ }^{2}$ Vinay Mulchandani, ${ }^{1}$ Swara Shah ${ }^{1}$}

${ }^{1}$ Department of Pedodontics and Preventive Dentistry, K.M. Shah Dental College and Hospital, Vadodara, Gujarat, India

${ }^{2}$ Department of Pedodontics and Preventive Dentistry, Karnavati School of Dentistry, Gandhinagar, Gujarat, India

\section{Correspondence to}

Dr Shital Kiran,

drshitalkiran@yahoo.com

Accepted 14 September 2015

\section{DESCRIPTION}

Supernumerary teeth are additional teeth present in dentition and are more common in permanent dentition, however, they are a rare finding in primary dentition ${ }^{1}$ and can be due to various genetic or environmental factors. The majority of supernumerary teeth seen in primary dentition are of a supplemental type and usually unilateral. Presence of supernumerary teeth has been noted in primary dentition but bilateral occurrence is rare. ${ }^{2}$

A 4-year-old girl with the symptoms of decayed teeth was brought to the dental clinic. Medical and family history was not significant. The patient had normal development and build for her age and sex. On clinical examination, an extra tooth was noted on either side of the maxillary quadrants, which mimicked, in shape and size, the lateral incisors more than they did the central incisors. These supplemental teeth were noted bilaterally mesial to the primary canines. Dental caries was noted in relation to 51, 52, 61 and 62 (figures 1-3). Intraoral periapical radiograph showed dental caries involving the pulp of 51 and 52 (figure 4). An orthopantomogram was taken to rule out other additional supernumerary teeth in the arches (figure 5). Bilateral supernumerary teeth mesial to primary canine was

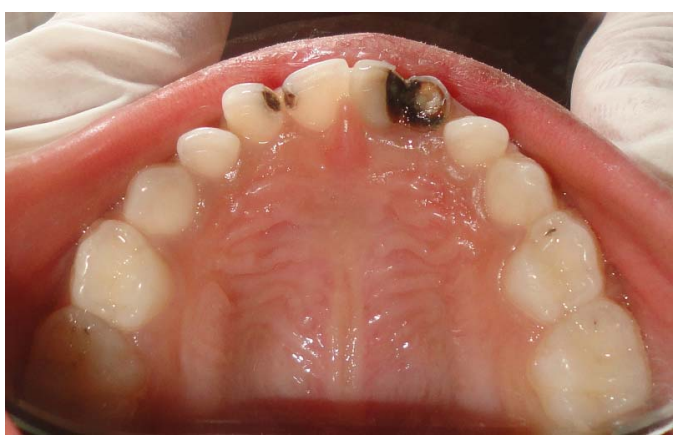

Figure 1 Maxillary arch showing supernumerary teeth bilaterally distal to central incisor teeth on either side.

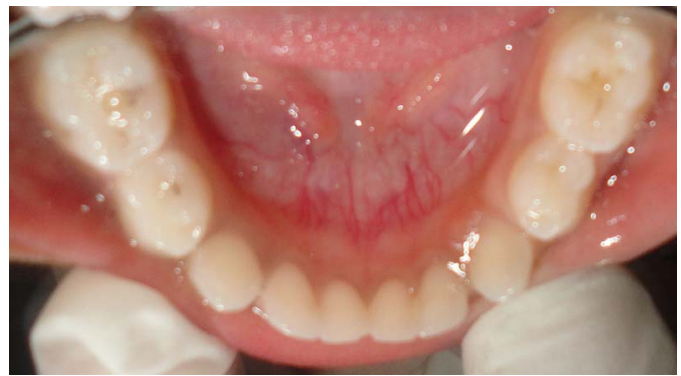

Figure 2 Mandibular arch photograph.

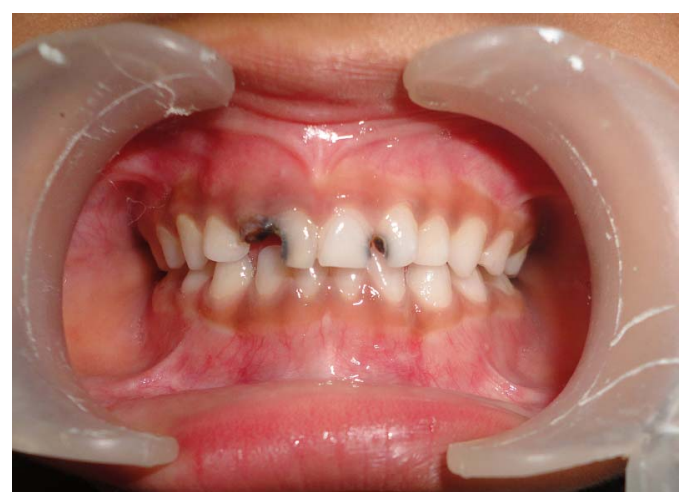

Figure 3 Occlusal view showing bilateral supernumerary teeth mesial to primary canines.

diagnosed based on the morphology of the primary lateral incisor crown, which was smaller in all dimensions compared to the supplemental; also, the roots of the supernumerary teeth appeared to be longer than those of the lateral incisors. Syndromes associated with supernumerary teeth

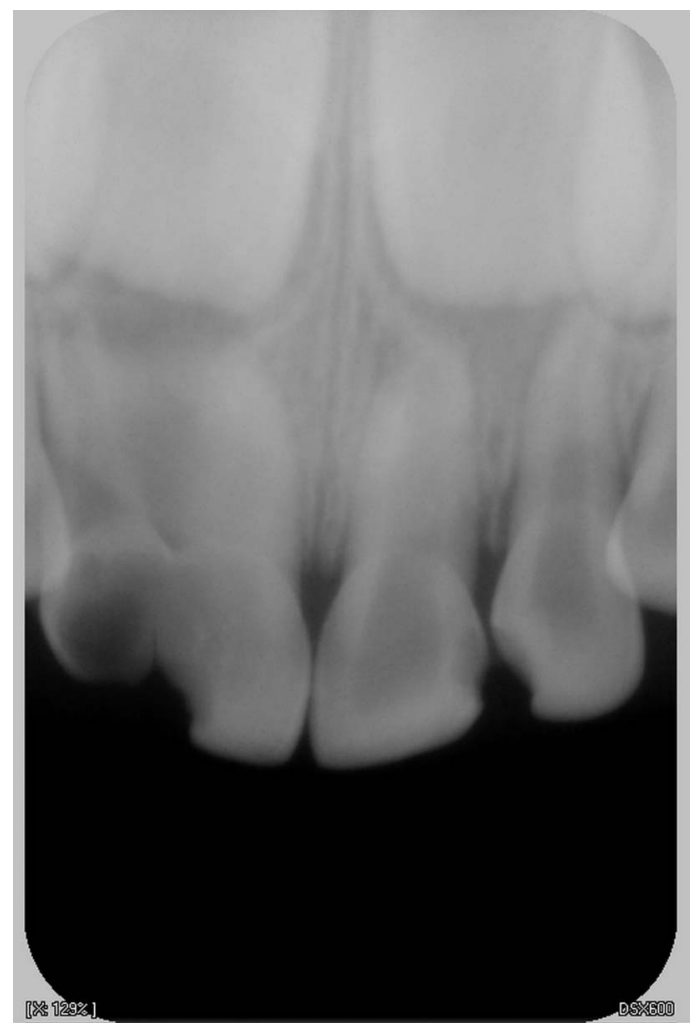

Figure 4 Intraoral periapical radiograph showing pulpal involvement of 51 and 52. 


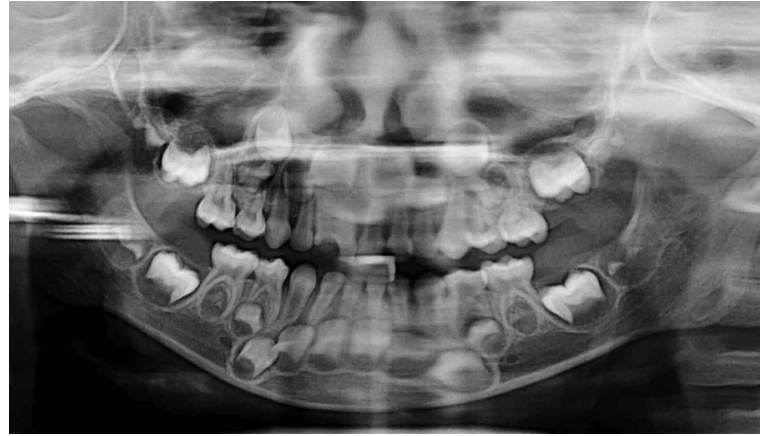

Figure 5 Orthopantomogram showing bilateral supernumerary teeth on left and right sides.

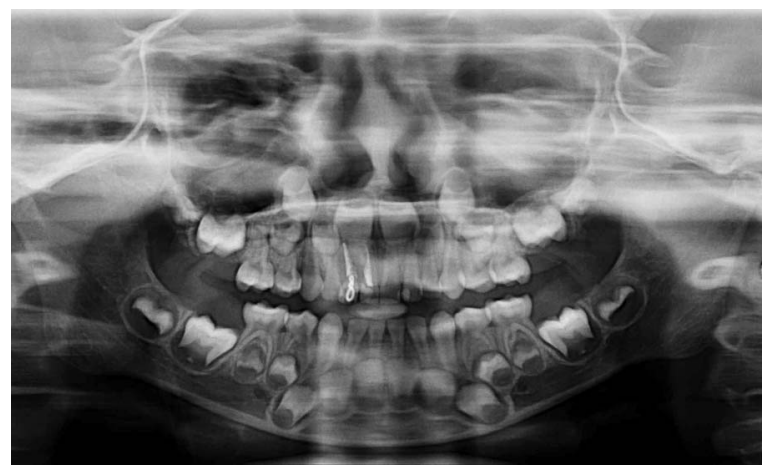

Figure 6 Orthopantomogram after pulpectomy of 51 and 52.

were ruled out by taking careful medical and family history and also by physical examination.

Oral prophylaxis followed by pulpectomy of 51 and 52, and restoration of 61 and 62, has been planned as treatment protocol. The bilateral supernumerary teeth are being kept under observation.

The rationale for maintaining the supernumerary teeth was based on the fact that no orthodontic treatment was possible and complete eruption of the teeth had already occurred. Pulpectomy of 51 and 52 was performed (figure 6) in order to prevent space loss and to avoid the need for future orthodontic treatment. Supernumerary teeth should be periodically observed; they can be maintained in the oral cavity provided they do not cause problems in function or aesthetics. ${ }^{2}$ When supernumerary primary teeth are identified, parents should be advised of the likely concerns to the permanent dentition. Also, important to remember is that these teeth resemble permanent dentition in $50 \%$ of cases. ${ }^{3}$

\section{Learning points}

- Supernumerary teeth can lead to diastema, malocclusion, rotation, crowding, failure of eruption of adjacent teeth and delay in eruption of successor teeth.

- The general dentist would usually be the first to notice supernumerary teeth; so early and regular check-ups for prompt diagnosis can be helpful in preventing issues with pathology and aesthetics.

- Prevalence rates of supernumerary teeth in deciduous dentition is $0.4-0.8 \%$, and for permanent dentition this ranges from $0.1-6.9 \%$.

\section{Competing interests None declared.}

Patient consent Obtained.

Provenance and peer review Not commissioned; externally peer reviewed.

\section{REFERENCES}

1 Bahadure RN, Thosar N, Jain ES, et al. Supernumerary teeth in primary dentition and early intervention: a series of case reports. Case Rep Dent 2012;2012:614652.

2 Shanmugha DG, Arannganal P, Muthu NS, et al. Supernumerary teeth associated with primary and permanent teeth: a case report. J Indian Soc Pedo Prev Dent 2002;20:104-6.

3 Levine N. The clinical management of supernumerary teeth. J Can Dent Assoc 1961;28:297-303.

Copyright 2015 BMJ Publishing Group. All rights reserved. For permission to reuse any of this content visit

http://group.bmj.com/group/rights-licensing/permissions.

BMJ Case Report Fellows may re-use this article for personal use and teaching without any further permission.

Become a Fellow of BMJ Case Reports today and you can:

- Submit as many cases as you like

- Enjoy fast sympathetic peer review and rapid publication of accepted articles

- Access all the published articles

- Re-use any of the published material for personal use and teaching without further permission

For information on Institutional Fellowships contact consortiasales@bmjgroup.com

Visit casereports.bmj.com for more articles like this and to become a Fellow 